\title{
DESCRIPTION OF PAIN IN NEWBORNS DURING BLOOD SAMPLING BASED ON VARIOUS PAIN MEASUREMENT
}

Kurniaty Ika Sari Tobing ${ }^{1 *}$, Yeni Rustina ${ }^{2}$

Afiliasi

1. Program Magister Ilmu Keperawatan, Fakultas Ilmu Keperawatan, Universitas Indonesia

2. Fakultas Ilmu Keperawatan, Universitas Indonesia

Dikirim 10 Februari 2020

Direvisi 12 Agustus 2020

Diterima 21 Agustus 2020

Dipublikasikan 30 November 2020

*Corresponding author

Email :

brave4kiki@gmail.com

\begin{abstract}
ABSTRAK
Bayi baru lahir dalam perawatan intensif menerima sejumlah prosedur invasif yang akan menyebabkan sensitisasi dan kemungkinan efek jangka panjang pada periode perkembangan anak selanjutnya. Hal tersebut mendorong kebutuhan metode pengkajian yang dapat mencerminkan respons nyeri yang aktual terutama dalam prosedur pengambilan sampel darah. Tujuan telaah literatur ini adalah untuk mendapatkan gambaran respons nyeri pada bayi baru lahir yang menerima prosedur invasif pengambilan sampel darah berdasarkan pengukuran nyeri yang berkembang saat ini.Pencarian literatur dilakukan melaluitiga database online, yaitu EBSCO (CINAHL dan MEDLINE), Scopus, dan Wiley dengan kata kunci terkait yang diterapkan adalah neonate/newborn, pain assessment/ pain measure/pain tool/pain instrument, invasive procedure/ blood sampling, pain intensity/ pain score. Telaah literatur ini mengidentifikasi dua belas artikel untuk ulasan kritis. Hasil telaah ini mampu memberikan informasi mengenai respons nyeri neonatus pada prosedur pengambilan darah melalui metode pengukuran perilaku dan aktivitas konduktansi kulit. Gambaran respons nyeri neonatus dengan pengukuran perilaku menunjukkan rentang nyeri ringan-sedang pada prosedur pengambilan darah melalui vena perifer, rentang nyeri sedang-berat pada penusukan tumit, dan rentang nyeri berat pada pengambilan darah arteri. Pengukuran konduktansi kulit mampu mencerminkan aktivitas simpatis terhadap stimulus nyeri melalui aktivitas kelenjar keringat di lapisan permukaan kulit, dan diharapkan menjadi metode objektif dalam pengukuran nyeri neonatus pada tataran klinis.
\end{abstract}

Kata kunci : prosedur invasif, neonatus, pengkajian nyeri, intensitas nyeri

\begin{abstract}
Newborns in intensive unit receives a number of invasive procedures that would causes changes in sensitizationof pain and possible long-term effects on child's subsequent developmental period. This encourages the need for pain measurement that could reflect the actual pain responses especially in blood sampling. The purpose of this review is to overview pain responses in newborns receiving procedures invasive of blood sampling using advance pain measurement. Literature search was conducted through three online database, namely EBSCO (CINAHL and MEDLINE), Scopus, and Wiley, within related keyword applied are invasive procedure, neonate, newborn, pain assessment and pain intensity. Twelve articles were identified for critical review. This literature study provides an overview of responses to blood collection procedures through measurements of behavioral and skin conductance activities in neonates. Pain response with behavioral measurement shows the range of mild-moderate pain in the procedure of blood sampling through peripheral veins, the range of moderate-severe pain in heel pricking, and the range of severe pain in arterial blood sampling. Skin conductance measurement reflect sympathetic activity to pain stimulus through sweat gland activity in the superficial layer of the skin, and is expected to be an objective method of pain measurement for neonates in clinical practice.
\end{abstract}

Keywords : invasive procedure, neonate, pain assessment, pain intensity

Sitasi jurnal :

Tobing, K.I. S., \& Rustina, Y. 2020. Description of pain in newborns during blood sampling based on various pain measurement. Jurnal Ilmu Keperawatan 8(2): 87-93 Doi: 10.21776/ub.jik.2020.008.02.4 


\section{PENDAHULUAN}

Bayi baru lahir akan menerima sejumlah paparan prosedur invasif, dengan frekuensi semakin meningkat seiring dengan rendahnya berat lahir dan usia gestasi bayi (Jeong, Park, Lee, Choi, \& Lee, 2014; Kassab, Alhassan, Alzoubi, \& Khader, 2019), sebagai konsekuensi perawatan intensif yang diberikan pada bayi (Jeong, Park, Lee, Choi, \& Lee, 2014). Paparan traumatik mempengaruhi perkembangan sistem syaraf pusat, sehingga dapat terjadi penurunan kemampuan inhibisi, perlambatan kecepatan konduksi dan aksi potensial sinaps, ketidakmampuan untuk mempertahankan rangsangan, insufisiensi diferensiasi sel, serta penurunan pembentukan dendrit dan sinaptogenesis, dimana kejadian tersebut dapat menimbulkan gangguan pada perkembangan otak bayi diawal kehidupannya (Gursul, Hartley, \& Slater, 2019). Prosedur invasif sebagai paparan nyeri apabila terjadi berulang selama periode neonatal akan mengakibatkan perubahan pada sensitisasi nyeri dan juga dampak jangka panjang seperti gangguan kognitif, perilaku dan emosi pada perkembangan selanjutnya saat usia sekolah (Doheny, 2017).

Pada bayi baru lahir yang mendapat perawatan intensif kurang dari tujuh hari, prosedur invasif yang sering digunakan adalah penusukan tumit dan vena perifer (Kassab, Alhassaan, Alzoubi, \& Khader, 2019), dalam pemeriksaan darah bayi. Dampak yang tidak diinginkan dari paparan nyeri saat periode neonatal ini mendorong kebutuhan akan pengukuran nyeri yang valid dan reliabel (Faye, Jonckheere, Logier, Kuissi, Jeanne, Rakza, et al., 2010). Pertanyaan yang memandu pencarian literatur dalam telaah ini adalah bagaimana respons nyeri bayi baru lahir pada prosedur invasif pengambilan darah yang ditunjukkan melalui pengkajian nyeri yang berkembang saat ini. Tujuan dari telaah literatur ini adalah untuk mendapatkangambaran respons nyeri pada bayi baru lahir yang menerima prosedur invasif pengambilan sampel darah menggunakan pengukuran nyeri yang berkembang saat ini. Telaah literatur ini diharapkan mampu memberikan informasi respons nyeri neonatus terhadap prosedur pengambilan darah, sehingga mampu memberikan penatalaksanaan yang tepat dalam pengelolaan nyeri pada neonatus.

\section{METODE}

Pencarian literatur onlinedatabase dari CINAHL dan MEDLINE (melalui EBSCO), Scopus, dan Wiley, dengan menerapkan kata kunci: neonate/ newborn, pain assessment/ pain measure/ pain tool/ pain instrument, invasive procedure/ blood sampling, pain intensity/ pain score, selama bulan NovemberDesember 2019. Tujuan dari telaah literatur ini adalah untuk mendapatkan gambaran respons nyeri terhadap prosedur invasif pengambilan darah pada bayi baru lahir selama dirawat di rumah sakit dengan menggunakan instrumen pengkajian nyeri neonatus dari 12 artikel yang didapatkan dalam pencarian literatur ini.

Hasil pencarian dilakukan pembacaan abstrak sebagai bentuk skrining sebelum dilakukan ulasan kritis artikel. Artikel yang dimasukkan dalam telaah literatur ini merupakan artikel lengkap terkait dengan pengukuran respons nyeri dengan menggunakan alat ukur selama prosedur pengambilan darah, jenis artikel penelitian, sumber jurnal, berbahasa Inggris, dan publikasi final. Telaah literatur ini mengeksklusikan artikel yang merupakan penelitian sponsor alat medis tertentu, analisis efikasi dari metode nonfarmakologis maupun farmakologis untuk mengurangi nyeri, prosedur invasif yang bukan prosedur pengambilan darah, penelitian tentang validitas instrumen pengukuran, serta penelitian tentang gambaran jumlah prosedur invasif.

Total artikel yang didapatkan berjumlah 1504 . Berdasarkan kriteria inklusi didapatkan hasil akhir yang dimasukkan kedalam telaah literatur ini sebanyak 12 artikel. Artikel penelitian yang didapat berasal dari negara Norwegia, Brazil, India, Selandia Baru, Turki, Polandia, Cina, Swedia, dan Amerika Serikat, dengan jumlah sampel bevariasi antara 10 hingga 100 bayi. Karakteristik sampel paling banyak pada bayi prematur, dan yang lainnya merupakan bayi cukup bulan, bayi yang dirawat di unit perawatan intensif, bayi baru lahir di ruang persalinan, hingga bayi yang terpasang ventilasi mekanik. Prosedur invasif pengambilan darah yang banyak digunakan dalam penelitian ini adalah penusukan tumit, prosedur lainnya adalah pengambilan darah melalui vena perifer dan arteri. Terdapat enam penelitian yang membandingkan skor nyeri dengan lebih dari satu instrumen pengukuran, dan sebanyak dua penelitian 
menggunakan pengukuran konduktansi kulit dalam mengidentifikasi nyeri neonatus, satu penelitian yang membandingkan respons nyeri dengan pengukuran konduktansi kulit yang dikombinasikan dengan instrumen pengukuran PIPP (Premature Infant Pain Profile), serta satu penelitian yang membandingkan respons nyeri dengan pengukuran konduktansi kulit dengan pengkajian perilaku nyeri NIPS (Neonatal Infant Pain Scale), NFCS (Neonatal Facial Coding System), dan COMFORT. Artikel yang didapat memiliki rentang waktu publikasi dari tahun 2007 hingga 2018, menggunakan rancangan penelitian observasi analitik, longitudinal, kohort, dan RCT (Randomized Controlled Trial) dengan fokus nyeri pada neonatus.

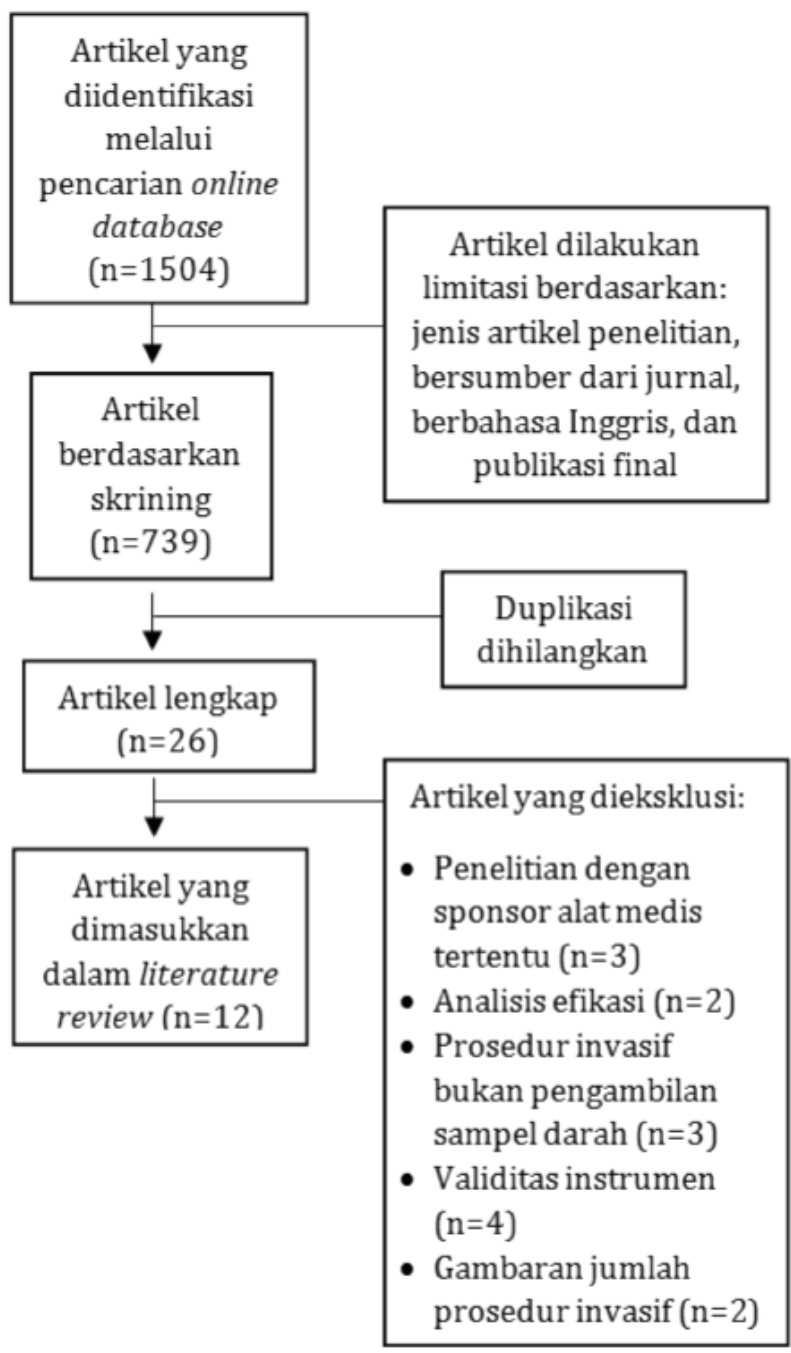

\section{Skema 1. Flowchart Pemilihan Artikel}

\section{HASIL}

Hasil pencarian literatur yang dilakukan, didapatkan alat ukur yang digunakan dalam pengkajian nyeri neonatus meliputi pengukuran kuantitatif dengan instrumen yang menggabungkan penilaian fisiologis dan perilaku, seperti NIPS (Neonatal Infant Pain Scale), PIPP (Premature Infant Pain Profile), serta pengukuran aktivitas konduktansi kulit. Premature Infant Pain Profile (PIPP) memiliki parameter penilaian nyeri yang terdiri dari tujuh komponen, meliputi tiga komponen perilaku (ekspresi wajah), dua komponen fisiologis (denyut jantung dan saturasi oksigen), dan dua komponen kondisional/ kontekstual (usia gestasi dan tingkat kesadaran) (Gibbins et al, 2014). Parameter penilaian nyeri yang digunakan pada Neonatal Infant Pain Scale (NIPS) terdiri dari lima parameter perilaku (ekspresi wajah, tangisan, kemampuan terjaga, pergerakan lengan dan kaki) dan tanda fisiologis (yaitu pola napas) (Aydin \& İnal, 2019). Pengukuran respons konduktansi kulit dengan penempelan elektroda monitor pada kulit bayi mampu merefleksikan aktivitas sistem saraf simpatis terhadap stimulus nyeri akut (de Jesus, Campos Júnior, Storm, da Rocha, \& Tristão, 2015). Instrumen pengukuran tersebut mampu menunjukkan gambaran respons nyeri pada bayi terhadap pengambilan darah selama bayi dirawat di rumah sakit.

Gambaran respons nyeri bayi pada beberapa lokasi penusukan pengambilan darah yang ditemukan dalam telaah literatur ini, meliputi penusukan tumit pada bayi baru lahir cukup bulan yang dilakukan Mathai, Naresh dan Sahu (2010) menunjukkan skor nyeri berat sebesar 6 dari 7 dengan pengkajian nyeri NIPS. Skor nyeri serupa terdapat dalam penelitian yang dilakukan oleh Gokulu et al (2016), bahwa penusukan tumit memiliki nilai NIPS 7 dari total skor 7 yang dikategorikan rentang nyeri berat. Penelitian yang dilakukan Britto, Jasmine, dan Rao (2017) dengan menggunakan instrumen PIPP, menunjukkan skor 7 dari total nilai PIPP 21, sedangkan penelitian Williams, Khattak, Garza, dan Lasky (2009) menunjukkan skor NIPS 5 dari 7, yang keduanya memberikan rentang nyeri sedang. Hal tersebut berbeda dari penelitian Eriksson, Storm, Fremming, dan Schollin (2007) yang menunjukkan rentang nyeri ringan dengan skor PIPP 6 dari 21. Penelitian lainnya yang dilakukan oleh O'Sullivan, Rowley, Ellis, Faasse, dan Petrie (2016) menggunakan instrumen PAT (Pain Assessment Tool) dan COVERS (Crying, Oxygen requirement, Vital signs, Expression, Resting, Signaling distress) menunjukkan rentang nyeri ringan dengan skor PAT 6 dari 20 dan nilai COVERS 4 dari 12. Cepuch et al (2018) menyatakan rentang nyeri ringan pada 
pengambilan darah kapiler dengan skor CRIES (Cry, Reuires increased oxygen administration, Increased vital signs, Expression, Sleeplessness) 3 dari 10.

Respons nyeri pada prosedur pengambilan darah dengan lokasi vena perifer dan arteri ditunjukkan pada beberapa penelitian, seperti yang dilakukan Cepuch, Kruszecka-Krowka, Biedra, dan Kozka (2018) dengan lokasi penusukan vena perifer memberikan rentang nyeri sedang dengan skor NIPS 5 dari 7. Penelitian lainnya ditunjukkan oleh Serpa, Guinsburg, Balda, dos Santos, Areco, dan Peres (2007), menunjukkan rentang nyeri ringan dengan skor NIPS 2 dari 7; sedangkan pada penelitian Cepuch et al menunjukkan rentang nyeri sedang dengan skor CRIES 5 dari 10. Hanya ditemukan satu penelitian yang melakukan pengukuran respons nyeri terhadap pengambilan darah arteri pada bayi baru lahir dengan instrumen PIPP, yaitu pada penelitian yang dilakukan Huang, Li, Zhou, He, Zhong, dan Wang (2018), menunjukkan rentang nyeri berat dengan skor PIPP 11 dari 21, skor N-PASS (Neonatal Pain Agitation Sedation Scale) 5 dari 11 dan NIAPAS (Neonatal Infant Acute Pain Assessment Scale) 8 dari 18.

Pengukuran respons nyeri dengan konduktansi kulit terhadap prosedur pengambilan darah ditunjukkan Pereira-da-Silva et (2012) dengan hasil respons konduktansi yang lebih lama pada prosedur penusukan tumit untuk analisis gas darah daripada penusukan tumit untuk pemeriksaan gula darah. Penelitian lainnya dilakukan Munsters, Wallstrom, Agren, Norsted, dan Sindelar (212), menunjukkan perbedaan indeks konduktansi antara bayi baru lahir dengan usia gestasi $<28$ minggu dan $\geq 28$ minggu terhadap stimulus nyeri penusukan tumit. Hasil penelitian tersebut menunjukkan nilai baseline 0,01 $\mu \mathrm{S}$ puncak/ detik dan saat penusukan tumit sebesar $0,11 \mu \mathrm{S}$ puncak/ detik pada bayi baru lahir dengan usia gestasi lebih dari 28 minggu; sedangkan pada bayi baru lahir dengan usia gestasi kurang dari 28 minggu memiliki nilai baseline $0,06 \mu \mathrm{S}$ puncak/ detik dan saat penusukan tumit $0,07 \mu \mathrm{S}$ puncak/ detik.

\section{PEMBAHASAN}

\section{Perubahan Perilaku dan Fisiologis Terkait Nyeri}

Nyeri dipersepsikan melalui proses nosisepsi, sebagai suatu respons fisiologis terukur dari reseptor khusus (nosiseptor) terhadap kerusakan jaringan yang aktual atau potensial dan dipersepsikan oleh sistem saraf pusat yang ditunjukkan melalui respons otonom seperti peningkatan tekanan darah atau respons perilaku seperti refleks menarik atau perilaku pertahanan lain yang lebih majemuk (Vardeh \& Naranjo, 2017). Ketidakmampuan neonatus mengungkapkan nyeri secara verbal menjadikan penilaian dilakukan dengan pengamatan yang meliputi perubahan perilaku dan fisiologis seperti ekspresi wajah meringis, menangis, gerak tubuh, kondisi terjaga, denyut jantung, laju nafas, saturasi oksigen, tekanan darah (Nedeljkovic \& Zaccagnino, 2017).

\section{Prosedur Invasif}

Prosedur tindakan dikatakan sebagai stimulus nyeri apabila menginvasi keutuhan tubuh neonatus atau yang mengakibatkan trauma pada kulit atau mukosa yang berasal dari masuk atau keluarnya benda asing pada jalan nafas, saluran pencernaan atau perkemihan (Carbajal et al., 2008). Penelitian yang dilakukan Cignacco et al (2008) menunjukkan 70\% tindakan yang dilakukan di NICU (Neonatal Intensive Care Unit) merupakan prosedur nyeri, dimana $44 \%$ diantaranya dikategorikan nyeri berat dengan instrumen VAS (Visual Analogue Scale) pada skor 6-10, salah satunya adalah prosedur pengambilan darah melalui penusukan tumit dan vena perifer. Hal serupa juga dikemukakan oleh Kassab, Alhassan, Alzoubi, dan Khader (2019), bahwa pada bayi baru lahir yang dilakukan perawatan intensif kurang dari tujuh hari, prosedur yang sering dilakukan adalah penusukan tumit dan penusukan vena perifer. Penusukan tumit yang dilakukan terhadap bayi prematur selama perawatan intensif terjadi sebanyak 36\% (Orovec, Disher, Caddell, \& Campbell-Yeo, 2018).

\section{Fokus Pengukuran Nyeri pada Neonatus}

Instrumen pengkajian nyeri pada neonatus yang banyak digunakan dalam penelitian terhadap prosedur invasif pengambilan darah adalah dengan mengamati perubahan pada parameter perilaku dengan fisiologis yang terjadi, seperti ekspresi wajah meringis, menangis, gerak tubuh, kondisi terjaga, denyut jantung, laju nafas, saturasi oksigen, dan tekanan darah (Nedeljkovic \& Zaccagnino, 2017). Salah satu instrumen yang menggunakan gabungan parameter perilaku dan fisiologis adalah Premature Infant Pain Profile (PIPP), dimana komponen penilaian yang terdapat pada PIPP konsisten dengan indikator perubahan fisiologis 
nyeri pada bayi, dan mampu menganalisis perubahan respons nyeri bayi prematur dan bayi cukup bulan (de Oliveira, de Jesus, \& Tristao, 2012). Pada penelitian yang dilakukan Bellieni et al (2007) menunjukkan bahwa penilaian PIPP cukup rumit karena perlu melibatkan monitoring yang cukup kompleks dan waktu dalam menilai setiap parameternya, misal durasi pergerakan wajah, perubahan denyut jantung dan saturasi, namun instrumen nyeri tersebut merupakan instrumen yang baik untuk penelitian karena peneliti tidak memerlukan pengkajian nyeri secara real-time. Komponen penilaian PIPP terdapat dua yang tidak subjektif yaitu usia gestasi dan arousal state (Bellieni et al, 2007), sehingga parameter penilaian lainnya akan dipengaruhi oleh subjektif penilai.

Instrumen lainnya yang menggunakan parameter perilaku dan fisiologis dalam penilaiannya adalah Neonatal Infant Pain Scale (NIPS). Pengukuran ini lebih disukai karena penggunaanya yang praktis (Fitz-James Antoine, Gritsenko, \& Carullo, 2017). Meskipun demikian, menurut Pereira-da-Silva et (2012) instrumen ini dipengaruhi oleh lama waktu dalam penilaiannya dan kemampuan penilai (bersifat subjektif).

Pengukuran lainnya dengan menilai proses fisiologis yang terjadi akibat stimulus nyeri adalah pengukuran konduktansi kulit. Respons nyeri dengan pengukuran konduktansi kulit melalui penelitian Bari, Aldosky, Tronstad, Kalvoy, dan Martinsen (2018), mengidentifikasi perubahan respons konduktansi kulit terhadap berbagai stimulus nyeri, dengan hasil terdapat peningkatan yang signifikan $(\mathrm{p}<0,001)$ terhadap perbedaan pemberian stimulus dengan TENS (Transcutaneus Electrical Nerve Stimulation) dimana terjadi rerata peningkatan respons konduktansi sebesar 4,3 $\mu \mathrm{S}$ pada tiap tingkatan intensitas TENS $(0,2 \mathrm{~V}, 0,3 \mathrm{~V}$, dan $0,4 \mathrm{~V})$, sehingga pengukuran ini dapat digunakan untuk monitoring kejadian nyeri.

Alat ini memerlukan perlekatan elektroda monitor dalam menangkap respons konduktansi kulit yang akan direkam pada monitor, yang dapat diletakkan pada beberapa bagian tubuh seperti pada jari tangan, pergelangan tangan (horisontal distal, horisontal pertengahan, dan arah vertikal), dada, tapak kaki, betis, dahi, leher, bahu, punggung, buttock, abdomen, ketiak, lengan atas, dan paha (van Dooren, de Vries, \& Janssen, 2012). Metode pengukuran ini mampu merefleksikan aktivitas sistem saraf simpatis terhadap stimulus nyeri akut (de Jesus, Campos Júnior, Storm, Da Rocha, \& Tristão, 2015).

\section{Gambaran Respons Nyeri Neonatus pada Prosedur Pengambilan Darah}

Hasil penelitian tersebut menunjukkan respons nyeri terhadap prosedur pengambilan darah dengan penusukan tumit memiliki rentang nyeri sedang-berat (Britto, Jasmine, \& Rao, 2017; Gokulu et al, 2016); sedangkan pengambilan darah melalui vena perifer pada rentang ringan-sedang (Cepuch, KruszeckaKrowka, Biedra, \& Kozka, 2018; Serpa, Guinsburg, Balda, dos Santos, Areco, \& Peres, 2007), dan pengambilan darah melalui arteri pada rentang nyeri berat (Huang, Li, Zhou, He, Zhong, \& Wang, 2018).

\section{KESIMPULAN}

Telaah literatur ini memperoleh gambaran respons nyeri pada prosedur pengambilan darah melalui pengukuran perilaku dan aktivitas konduktansi kulit pada neonatus. Instrumen pengukuran perilaku nyeri seperti PIPP (Premature Infant Pain Profile) dan NIPS (Neonatal Infant Pain Scale) memiliki parameter penilaian yang konsisten dengan indikator perubahan fisiologis nyeri pada neonatus, namun dipengaruhi oleh lama waktu penilaian dan kemampuan penilai (bersifat subjektif). Respons nyeri neonatus terhadap prosedur pengambilan darah berdasarkan pengukuran perilaku menunjukkan rentang nyeri ringan-sedang pada prosedur pengambilan darah melalui vena perifer, rentang nyeri sedang-berat pada penusukan tumit, dan rentang nyeri berat pada pengambilan darah arteri. Pengukuran respons nyeri lainnya melalui konduktansi kulit mampu digunakan untuk monitoring kejadian nyeri dengan merefleksikan aktivitas simpatis terhadap stimulus nyeri melalui aktivitas kelenjar keringat pada lapisan superfisial kulit, sehingga diharapkan mampu menjadi metode pengukuran nyeri yang objektif pada tataran klinis. 


\section{DAFTAR PUSTAKA}

Aydin, D. and İnal, S. (2019) 'Effects of breastfeeding and heel warming on pain levels during heel stick in neonates', International Journal of Nursing Practice, 25(3), pp. 1-8. doi: 10.1111/ ijn.12734.

Bari, D. S. etal. (2018) 'Electrodermal activity responses for quantitative assessment of felt pain', Journal of Electrical Bioimpedance, 9(1), pp. 52-58. doi: 10.2478/joeb-2018-0010.

Bellieni, C. V. et al. (2004) 'Cry features reflect pain intensity in term newborns: an alarm threshold', Pediatric Research, 55(1), pp. 142-146. doi: 10.1203/01.PDR.0000099793.99608.CB.

Bellieni, C. V. et al. (2007) 'Inter-observer reliability of two pain scales for newborns', Early Human Development, 83(8), pp.549-552. doi: 10.1016/j. earlhumdev.2006.10.006.

Britto, C., Jasmine and Rao, S. P. N. (2017) 'Assessment of neonatal pain during heel prick: Lancet vs needle-A randomized controlled study', Journal of Tropical Pediatrics, 63(5), pp. 346-351. doi: 10.1093/tropej/fmw093.

Carbajal, R. et al. (2008) 'Neonates in intensive care units epidemiology and treatment of painful procedures in prevention of pain in neonates epidemiology and treatment of painful procedures in neonates in intensive care units', JAMA Pain Pediatrics Neonatology and Infant Care Drug Therapy; Drug Therapy, Other Related Letters . JAMA Ricardo Carbajal et al. In Reply: . JAMA Praveen Kumar, 300300300(11919). doi: 10.1001/jama.300.1.60.

Cepuch, G. et al. (2018) 'The exposure of premature newborns with respiratory failure to pain and touch on the first day of hospitalization in the neonatal intensive care unit - Pilot study', Family Medicine and Primary Care Review, 20(4), pp. 327-331. doi: 10.5114/fmpcr.2018.79342.

Cignacco, E. et al. (2008) 'Routine procedures in NICUs: Factors influencing pain assessment and ranking by pain intensity', Swiss Medical Weekly, 138(33-34), pp. 484-491.

van Dooren, M., de Vries, J. J. G. G. J. and Janssen, J. H. (2012) 'Emotional sweating across the body: Comparing 16 different skin conductance measurement locations', Physiology and Behavior. Elsevier Inc., 106(2), pp. 298-304. doi: 10.1016/j.physbeh.2012.01.020.

Fitz-James Antoine, I. A., Gritsenko, K., and Carullo, V. (2017). 'Development of pain systems' in Yong, R. J., Nguyen, M., Nelson, E., \& Urmn, R. D (eds.) Pain medicine: An essential review (11-13). Swizerland: Springer, pp. 11-13.

Doheny, K. K. (2017). 'Long-term consequences of pain and stress in neonates' in Buonocore, G., \& Bellieni, C. V (eds.) Neonatal pain: Suffering, pain, and risk of brain damage in the fetus and newborn. Switzerland: Springer, pp. 213-225.

Eriksson, M. et al. (2007) 'Skin conductance compared to a combined behavioural and physiological pain measure in newborn infants', Acta Paediatrica, International Journal of Paediatrics, 97(1), pp. 27-30. doi: 10.1111/j.16512227.2007.00586.x.

Faye, P. M. et al. (2010) 'Newborn infant pain assessment using heart rate variability analysis', Clinical Journal of Pain, 26(9), pp. 777-782. doi: 10.1097/AJP.0b013e3181ed1058.

Gibbins, S. et al. (2014) 'Validation of the Premature Infant Pain Profile-Revised (PIPP-R)', Early HumanDevelopment.ElsevierLtd,90(4),pp.189193. doi: 10.1016/j.earlhumdev.2014.01.005.

Gokulu, G. et al. (2016) 'Comparative heel stick study showed thatnewborninfants whohad undergone repeated painful procedures showed increased short-term pain responses', Acta Paediatrica, International Journal of Paediatrics, 105(11), pp. e520-e525. doi: 10.1111/apa.13557.

Gursul, D., Hartley, C. and Slater, R. (2019) 'Nociception and the neonatal brain', Seminars in Fetal and Neonatal Medicine. Elsevier, 24(4), p. 101016. doi: 10.1016/j.siny.2019.05.008.

Huang, X. Z. et al. (2018) 'Evaluation of three pain assessment scales used for ventilated neonates', Journal of Clinical Nursing, 27(19-20), pp. 35223529. doi: 10.1111/jocn.14585.

Jeong, I. S. oo. et al. (2014) 'The frequency of painful procedures in neonatal intensive care units in South Korea', International journal of nursing practice, 20(4), pp. 398-407. doi: 10.1111/ ijn.12202. 
de Jesus, J. A. L. et al. (2015) 'Skin conductance and behavioral pain scales in newborn infants', Psychology and Neuroscience, 8(2), pp. 203-210. doi: 10.1037/h0101058.

Kassab, M. et al. (2019) 'Number and frequency of routinely applied painful procedures in university neonatal intensive care unit', Clinical Nursing Research, 28(4), pp. 488-501. doi: $10.1177 / 1054773817744324$.

Mathai, S. S., Naresh, A., and Sahu, S. (2010) 'Behavioral response to pain in drowsy and sleeping neonates: A randomized control study', Indian Pediatrics, pp. 390-392. doi: 10.1007/s13312-011-0082-1.

Munsters, J. et al. (2012) 'Skin conductance measurements as pain assessment in newborn infants born at 22-27weeks gestational age at different postnatal age', Early Human Development. Elsevier Ltd, 88(1), pp. 21-26. doi: 10.1016/j.earlhumdev.2011.06.010.

Nedeljkovic, S. S., and Zaccagnino, M. P. (2017). 'Pain assessment' in Yong, R. J., Nguyen, M., Nelson, E., \& Urmn, R. D (eds.) Pain medicine: An essential review. Swizerland: Springer, pp. 33-37.

de Oliveira, M. V. M., de Jesus, J. A. L. and Tristao, R. M. (2012) 'Psychophysical parameters of a multidimensional pain scale in newborns', Physiological Measurement, 33(1), pp. 39-49. doi: 10.1088/0967-3334/33/1/39.

Orovec, A. et al. (2019) 'Assessment and management of procedural pain during the entire neonatal intensive care unit hospitalization', Pain Management Nursing. American Society for Pain Management Nursing, (xxxx). doi: 10.1016/j.pmn.2018.11.061.
O'Sullivan, A. T. et al. (2016) 'The validity and clinical utility of the covers scale and pain assessment tool for assessing pain in neonates admitted to an intensive care unit', Clinical Journal of Pain, 32(1), pp. 51-57. doi: 10.1097/ AJP.0000000000000228.

Pereira-Da-Silva, L. et al. (2012) 'Skin conductance indices discriminate nociceptive responses to acute stimuli from different heel prick procedures in infants', Journal of Maternal-Fetal and Neonatal Medicine, 25(6), pp. 796-801. doi: 10.3109/14767058.2011.587919.

Serpa, A. B. M. et al. (2007) 'Multidimensional pain assessment of preterm newborns at the 1st, 3rd and 7th days of life', Sao Paulo Medical Journal, 125(1), pp. 29-33. doi: 10.1590/s151631802007000100006.

Slater, R. et al. (2008) 'How well do clinical pain assessment tools reflect pain in infants?', PLoS Medicine, 5(6), pp. 0928-0933. doi: 10.1371/ journal.pmed.0050129.

Vardeh, D., \& Naranjo. (2017). 'Anatomy and physiology: Mechanism of nociceptive transmission' in Yong, R. J., Nguyen, M., Nelson, E., \& Urmn, R. D (eds.) Pain medicine: An essential review. Swizerland: Springer, pp. 3-5.

Williams, A. L. et al. (2009) 'The behavioral pain response to heelstick in preterm neonates studied longitudinally: Description, development, determinants, and components', Early Human Development. Elsevier Ireland Ltd, 85(6), pp. 369-374. doi: 10.1016/j. earlhumdev.2009.01.001. 